\title{
Educational Trajectories and Health over the Life Course: A Role for the DSBN Academy?
}

\author{
Nicole Etherington \\ University of Western Ontario, Department of Sociology
}

Research demonstrates that despite post-secondary expansion, there are still vast socioeconomic differences in educational attainment. Educational attainment can have a tremendous impact on the life course in terms of income, employment, and perhaps most significantly, health. Recognizing these issues, the Niagara region opened the DSBN Academy in September 2011. The DSBN Academy, the first school of its kind in Canada, offers social and academic programming designed to encourage its students to not only graduate from high school, but also, to become the first in their family to pursue post-secondary education. From a life course perspective, this paper assesses the relationship between education and health followed by an examination of the primary processes of cumulative advantage and disadvantage involved in producing variation in educational trajectories, which in turn impact health outcomes. I then evaluate the role of the DSBN Academy as a potential strategy to facilitate the completion of higher education by working-class students, and accordingly, to improve their health outcomes. Through analyzing the Academy, I argue that while the school has the potential to be a turning point in the lives of its students, it also risks committing a form of Bourdieu's symbolic violence. That is, it enforces middle-class ideals of education and good health as both desirable and indicators of success. Consequently, this paper raises a fundamental question in the study of social inequality, namely, how sociologists can work toward ameliorating inequality without perpetuating the symbolic violence we continually fight against.

Keywords: sociology; sociology of education; life course; DSBN academy

Les recherches démontrent que, malgré le développement de l'enseignement postsecondaire, il existe encore de grandes différences socio-économiques en matière de niveau d'études. Le niveau d'études peut avoir un impact énorme dans un parcours de vie en termes de revenus, d'emploi, et peut-être plus important encore, de santé. Conscient de ces enjeux, la région du Niagara a ouvert la DSBN Academy en septembre 2011. La DSBN Academy, la première école du genre au Canada, offre des programmes sociaux et des programmes d'études conçus pour encourager ses élèves à non seulement obtenir leur diplôme d'études secondaires, mais également à devenir les premiers de leur famille à poursuivre des études postsecondaires. Dans la perspective d'une trajectoire de vie, cette étude évalue la relation entre l'éducation et la santé suivie d'un examen des principaux processus des avantages et désavantages cumulatifs liés qui jouent un rôle dans la variation du parcours scolaire, ce qui à son tour a des impacts sur l'état de santé. J'ai ensuite évalué le rôle de la DSBN Academy; le fait de l'intégrer peut-être une stratégie possible pour faciliter l'achèvement de l'enseignement supérieur par les étudiants de la classe ouvrière et, par conséquent, améliorer leur état de santé. Mon analyse de l'Académie me permet de soutenir que, même si l'école peut représenter un tournant dans la vie de ses élèves, elle risque aussi de commettre une forme de violence symbolique telle que celle définie par Bourdieu. Autrement dit, cela favorise les idéaux de la classe moyenne en matière d'éducation et de bonne santé comme étant à la fois souhaitable et indicateurs de succès. Par conséquent, ce document soulève une question fondamentale dans l'étude des inégalités sociales, à savoir, comment les sociologues peuvent chercher à estomper l'inégalité sans perpétuer la violence symbolique contre laquelle nous continuons de nous battre.

Mots-clés: sociologie; sociologie de l'éducation; parcours de vie; DSBN Academy 
Research has long demonstrated the connection between socioeconomic stratification and health inequality (e.g. Phelan, Link \& Tehranifar, 2010). This relationship has also been shown to begin in early life, with initial relative advantage influencing divergent health patterns across individuals or groups over time (O'Rand, 1996). Referred to as cumulative advantage and disadvantage (CAD), this perspective advances conceptions of health inequality through its attention to processes of accumulation and change over the life course (for a review, see Seabrook \& Avison, 2012). Accordingly, the link between childhood conditions and adult health outcomes is made salient as the cumulative effects of advantage and disadvantage are found to produce differing health trajectories. The experience of childhood poverty, for example, has been linked to such negative health outcomes as cardiovascular disease, lung function, and chronic morbidity in later adult life (e.g. Svanes et al., 2010; Ferraro, 2011). This has largely been attributed to the roles of protective and risk factors, whereby those of higher socioeconomic status (SES) have greater access to resources, such as higher education, which enable them to avoid many sources of health adversity (e.g Hatch, 2005). Conversely, those individuals who do not graduate successfully from a post-secondary institution are more likely to experience deleterious effects in later life, including poor physical and mental health (O'Rand, 1996; Mirowsky \& Ross, 2003).

Given that education is integral to one's life opportunities, the District School Board of Niagara (DSBN) opened the DSBN Academy in September 2011. Indeed, disadvantaged students from poor and working-class homes are at a higher risk of dropping out from high school and not attending university or college (Knighton \& Mirza, 2002). This is quite salient in the Niagara Region, where only one in five people over the age of twenty-four have a university education, compared to Ontario's rate of one in three (Hammer, 2011). Furthermore, 5400 students in Niagara live in poverty (Hammer 2011). In an attempt to reduce these socioeconomic educational barriers, the DSBN Academy offers social and academic programming designed to encourage its students to not only graduate from high school, but also, to become the first in their family to pursue post-secondary education. Such strategies include: a single-track academic program, mandatory parental involvement, transportation, a school-wide focus on post-secondary preparation, mentoring opportunities, and a breakfast and lunch program (DSBN Academy, 2012). Ultimately, the Academy aims to provide disadvantaged students in Niagara with educational opportunities they may not have otherwise had. As a result, the school could serve as a pivotal turning point in the lives of Niagara's disadvantaged students, affecting their educational trajectories, and subsequently producing positive health benefits.

Accordingly, this paper will theoretically evaluate the potential role of the DSBN Academy in affecting the health trajectories of its students by boosting their educational attainment. First, processes of cumulative advantage and disadvantage will be outlined with regard to health. Second, the ways in which CAD are manifested in the education system will be examined. Third, the consequences of educational variation for health outcomes will be outlined. Finally, the role of the DSBN Academy in reversing disadvantaged health trajectories through improving access to education will be assessed. It should be noted that the term "health" encompasses both physical and mental dimensions, and both are impacted by educational attainment. Ultimately, it will be determined that the Academy could be a crucial turning point for disadvantaged individuals if it can succeed in accomplishing its goals of increased post-secondary participation while respecting the working-class identities of its students.

\section{Cumulative Advantage/Disadvantage and Health}

An individual's social background has important implications for their life course outcomes. One way in which to conceptualize this link between early and late life, particularly in terms of health, is through processes of cumulative advantage and disadvantage. According to a CAD perspective, initial advantage or disadvantage is amplified or compounded over time to produce heterogeneity in life course trajectories (Willson et al., 2007). This means that advantages or disadvantages accumulate over time, and in so doing, produce health trajectories that diverge with age. For example, the rate of decline in functional capacity is accelerated for individuals from disadvantaged backgrounds and delayed for their initially advantaged counterparts (Kalache \& Kickbusch, 1997). Consequently, the relationship between health and 
socioeconomic status that begins in early life becomes magnified with age as a result of the effects of CAD (O'Rand, 1996). Those children from higher socioeconomic backgrounds have a greater opportunity to obtain access to resources and can avoid many sources of adversity (Hatch, 2005). As a result, they are far more likely to experience positive health outcomes. Conversely, exposure to economic and social deprivation in childhood accumulates over time and creates growing disadvantage in adulthood and later life. The health gap between advantaged and disadvantaged individuals, therefore, widens over time, with early socioeconomic circumstances playing a key role in the exacerbation of these inequalities.

Early childhood disadvantage in the form of low SES has been found to be a predictor of numerous poor adulthood health outcomes, including cardiovascular disease, stroke, respiratory disease, stomach cancer, high Body Mass Index (BMI), decreased lung function, depressive symptoms, chronic morbidity, and compromised dental health (Mirowsky, Ross \& Reynolds, 2000; Black, Hayward \& Crimmins, 2001; Poulton et al., 2002; Galobardes, Lynch \& Smith, 2004; Mishra et al., 2004; Graham \& Power, 2004; Packard et al., 2011). Children who grow up in disadvantaged conditions are also more likely to develop negative mental health outcomes (e.g. McLeod \& Pavalko 2008) in addition to low birth weight, which is associated with obesity, diabetes, hypertension, and heart disease in later life (Ferraro, 2011). Early disadvantage is also associated with negative effects on the immune system, which increase the propensity to develop a number of chronic diseases in later life (Packard et al., 2011). Finally, the death rate for those adults who lived in poor socioeconomic conditions in childhood is double that of those from a high socioeconomic background (Kuh et al., 2006). In short, the cumulative effects of initial social position on negative health outcomes are apparent.

\section{Cumulative Disadvantage in the Education System: Implications for Health}

The impact of CAD is further demonstrated by the tendency for middle- and upper-class children to enter adulthood not only in better health, but also, with higher educational attainment (Haas 2006). As a result, those with higher SES have far greater access to health-protective resources than children from poor and working-class homes (e.g. Smith, 2005). Simply put, initial disadvantage in the form of low socioeconomic background can be further exacerbated by barriers in the education system. These barriers can inhibit educational attainment, and can therefore have important implications for individuals' health trajectories. In this section, I will review some of the ways in which poor and working-class students are further disadvantaged by the education system and the implications this may have for health outcomes later in life. Symbolic Violence: Implications of Capital for Learned Effectiveness and Health

Education is certainly a means of social and cultural capital in that it generates both formal and informal knowledge and skills that can directly affect the life course, especially with regard to health. One example of capital transmitted through the school system is learned effectiveness, or one's sense of personal control and effective agency (Mirowsky \& Ross, 2003). According to Mirowsky and Ross (2003: 26), "education gives people the resources to control and shape their own lives in a way that protects and fosters health". This is accomplished through the development of cognitive, communication, analytical, and problem-solving skills. These skills then enable individuals to become "more effective users of information," (Mirowsky \& Ross, 2003, p. 53) and as individuals learn to solve problems through gathering and interpreting information, their sense of control over their own lives increases. Indeed, a higher sense of personal control has been reported amongst those with higher levels of education (Mirowsky \& Ross, 2003). Accordingly, sense of control improves health outcomes largely because it promotes a healthy lifestyle. That is, those who feel that they are in control of their own lives tend to exercise more, drink moderately, avoid smoking, and are less likely to be overweight (Mirowsky \& Ross, 2003). Furthermore, sense of control is quite significant in determining one's mental health, as it is related to flexible coping styles, resilience, and apt emotionality (Ross \& VanWilligen, 1997).

Several additional studies provide empirical evidence that appears to support Mirowsky and Ross's (2003) argument concerning learned effectiveness in terms of individuals' abilities to exercise control over their health outcomes. In their study of individuals living with either HIV or diabetes, Goldman and Smith (2002) found that those with greater education were more likely to comply with complex treatment 
regimens. It has also been found that the well-educated more readily use "new information and medical interventions, such as Pap smears and mammograms, developed to improve health" (Pampel 2009: 529). Additionally, Paeratakul et al. (2002) report that college graduates are 3.6 times as likely as high school graduates to indicate paying fair or a lot of attention to nutritional information. Finally, individuals with higher education appear to have less difficulty enduring short-term stress for long-term gain (Thoits, 2006). This means that the higher educated are more likely to quit smoking, reduce alcohol consumption, and eat healthy (Wu \& Ross, 1995). Evidently, with a higher level of education comes a greater sense of learned effectiveness, which can serve as a form of capital that enhances health throughout the life course. This form of capital is particularly valuable given that once it is obtained, it is relatively inalienable. In other words, the skills acquired through education "inhere in the person" and are relatively long-lasting (Mirowsky \& Ross, 2003:27).

Evidently, education can provide individuals with important forms of cultural capital that enhance their health outcomes in later life. Yet, the ability to successfully navigate educational institutions inherently depends upon one's initial social and cultural capital, as acquired through family background. Consequently, the education system ensures the sustainability of the dominant class as these children possess the necessary "social and cultural cues" to negotiate their educational experience prior to entering school (Lamont \& Lareau 1988: 155). Conversely, working-class children must acquire these same skills after entering school, and even if they do so, they cannot achieve the institutional familiarity of their middleclass peers. Thus, middle-class children obtain greater educational benefits than their working-class peers, and the school system legitimates this practice. In fact, the failure of working-class students to advance is attributed to individual inabilities rather than discrepancies in cultural resources (Lamont \& Lareau 1988).

The embodiment of middle class culture by the school system and its subsequent tendency to impose these values onto working-class students is conceptualized as symbolic violence (Bourdieu, Passeron \& Nice, 1990). Here, the education system views the cultural capital of the middle class as the only natural and proper form of capital, and takes for granted that all students have equal access to it. In making this assumption a particular cultural system becomes imposed on working-class students and can prevent them from advancing through the education system with the ease of their middle-class peers. Specifically, middle-class cultural capital can be found in the evaluative criteria of schools wherein the educational norms of the dominant class are imposed in a manner most favourable to its own children while those of the working class are excluded (Lareau \& Weininger 2003). For example, the education system enforces institutionally sanctioned forms of language, while "de-legitimizing popular and subcultural vernaculars" (Halasz \& Kaufman, 2008: 312). In other words, if a student wishes to succeed in an education system which privileges the dominant culture, he or she must learn how to "talk smart" (Kaufman, 2003: 489). Indeed, all forms of assessment, including exams, essays, and presentations, require a certain linguistic capital, which largely differs according to social class (Bourdieu, Passeron, \& Nice 1990; Halasz $\&$ Kaufman 2008). Furthermore, public school curriculum tends to ignore children's literacy practices that occur outside of school (Knobel \& Lankshear, 2003; Luke \& Luke, 2001; Marsh, 2006). That is, "the world of the classroom, where "polished' language is used, contrasts with the world of the family" (Bourdieu et al., 1965: 9). As a result, the education system covertly distinguishes and differentiates between students in a manner that is "arbitrary, relative, and value-laden" (Grenfell, 2009: 443). The academic performance of students is then rewarded by virtue of their social background as it is mistaken for merit (Grenfell, 2009; Halasz \& Kaufman, 2008). Working-class children can then come to see the success of their middle-class peers as a result of "natural" ability or hard work. In reality, however, these discrepancies in achievement are largely the result of differential access to resources rather than individual deficiencies.

The forms of capital, or resources, to which individuals have access as they interact in the social world are shaped by their habitus. Bourdieu (1979: vii) describes the habitus as "a system of durable, transposable dispositions which functions as the generative basis of structured, objectively unified practices". This means individuals' social locations provide them with certain dispositions toward the world. Individuals internalize the culture of the group to which they belong, and this acts as a basis for all subsequent behaviour. The impact of the habitus on socialization practices is made tangible in Lareau's (2003) observational study of twelve working- and middle-class families. Depending on whether families 
were middle- or working-class, parents engaged in one of two strategies. Middle-class parents engaged in "concerted cultivation," which focuses on developing children's talents, opinions, and skills, typically through a variety of organized activities. Capital is then passed on from parent to child. Conversely, working-class and poor parents engaged in "the accomplishment of natural growth." The natural growth approach places value on providing for children's basic needs and offering support. Concerted cultivation is not viewed as an essential parental responsibility. Rather, the steps to get children through the day are given more importance.

These approaches result in differential types of "social competence" being transmitted to children (Lareau, 2003: 6). Middle-class children develop important life and basic job skills through organized activities. They are also encouraged to reason and use language effectively, fostering a large vocabulary and wide-ranging knowledge. Accordingly, middle-class children feel comfortable interacting with professionals and within institutions, including the education system. Their social skills and extracurricular involvement also tend to be "viewed more positively by society" (Lareau, 2003: 241). Indeed, the dominant middle-class culture tends to be valued by the school system (Halasz \& Kaufman, 2008). Conversely, the experiences of working-class and poor children are "not equally valued in institutional worlds" (Lareau, 2003: 241). These children experience an ever-present sense of financial and institutional constraint. They do not learn to reason or negotiate in the same way that middle-class children do, and do not develop the same verbal skills, inhibiting their formal interactions. Children are also not afforded the same extracurricular opportunities as their middle-class peers, limiting the socially valued skills they can develop. This is largely due to the fact that daily tasks cause greater strain on a families' resources among the poorer working-class.

Lareau (2003) also reports that teachers from schools in both working-class and middle-class neighborhoods advocated concerted cultivation, demonstrating the premium placed on middle-class values. Lareau's findings can be interpreted as evidence supporting Bourdieu's (1974) contention that the school system exhibits a middle-class habitus while committing symbolic violence against working-class students. After all, students with the habitus of the dominant class are more likely to succeed in the education system as they possess certain attributes that their working-class counterparts do not (Roscigno \& AinsworthDarnell, 1999). Confidence, charisma, and eloquent speech, for instance, are traits developed through a middle-class habitus that translate into academic rewards (Bourdieu, Passeron, \& Nice, 1990; Lareau, 2003; Halasz \& Kaufman, 2008). In fact, the way one looks, sits, stands, speaks, and so forth, can have important implications in terms of his or her interactions with teachers in the classroom, and ultimately, his or her life outcomes as determined by educational attainment (Toshalis, 2010).

Based on the situation described above, it is not surprising that low-income and working-class youth are more likely to drop out of high school and less likely to pursue post-secondary education (Lambert et al., 2004). When an individual does not have the cultural capital favoured by the school system and does not feel that his or her experiences are valued or recognized in this environment, feelings of not belonging and low ability can result. This, of course, has significant implications for health throughout the life course. Indeed, children who lack the necessary capital to succeed in the education system are less likely to accrue the additional capital higher education has to offer in terms of learned effectiveness and its corresponding health benefits. Symbolic violence is therefore one source of variation in the divergent educational and health outcomes of poor and working-class individuals as compared to middle- and upper-class individuals.

\section{Streaming and Tracking: Post-Secondary Paths and Health Resources}

In addition to symbolic violence, students from initially disadvantaged backgrounds also face processes of streaming and tracking in elementary and high school, which can severely restrict their ability to pursue higher education and obtain the health resources associated with it. As Hilmert and Jacob (2010) point out, an individual's final educational attainment is the result of a series of steps taken and decisions made throughout his or her academic career. Therefore, it is one of these early courses of action that can have the greatest impact on a student's life, rather than simply the final step. That is, the educational qualification a 
student ultimately receives at the end of their academic life is due to selective processes over the course of the time spent in the education system.

A child's family background plays a critical role in his or her educational success. Indeed, parental educational attainment has been shown to be the most important predictor of university participation (Knighton \& Mirza, 2002). Of course, family background also determines how much and which kinds of capital are passed on to children, which again influences their ability to be successful in the education system (Bourdieu, Passeron, \& Nice, 1990; Lareau, 2003; Lehmann, 2008). Implicated in these findings are the barriers faced by poor and working-class children in the education system, which are most significant in the early years, with only the brightest progressing to higher levels (Hilmert \& Jacob, 2010). Most lower class students, on the other hand, become trapped by the tracking system.

Tracking is defined as "the process whereby students are divided into categories so that they can be assigned in groups to various kinds of classes" (Oakes, 2005: 3). Simply put, students are identified as "fast" or "slow" learners, and placed into classes based on this ascribed ability. Proponents of this process argue that placing students with similar abilities into groups facilitates easier instruction as teachers can hone in on particular needs (Oakes, 2005). In fact, educators tend to "believe that students learn better in groups with others like themselves" (Oakes, 2005: 4). Despite these good intentions, however, tracking processes are laden with class inequality, as the majority of students in high-track classes are not only white, but also, from a middle-class background. Conversely, lower tracks air comprised mainly of lowincome/working-class students (Oakes, 2005).

Depending upon which track a student is placed in, curriculum content and quality of instruction can be quite different. In Oakes's (2005) major study of 300 tracked math and English classes in 25 American high schools, several important discrepancies were revealed. Students in high-track English classes were exposed to "high-status" knowledge in the form of great classic and modern works of literature, numerous expository writing assignments, thematic analyses, and advanced vocabulary. Lower-track students, however, read young adult fiction in their English classes, which are short and of low difficulty. Furthermore, they were taught basic reading skills via workbooks and kits. Similarly, low-track math classes focused on "basic computational skills and arithmetic facts" in comparison to the mathematical ideas and concepts taught in the higher-tracks (Oakes, 2005: 77). Thus, higher-track students were taught critical thinking and problem-solving skills, or the foundations of learned effectiveness, whereas lowertrack students were expected only to perform simple memorization and comprehension tasks.

These differences in expectations and curriculum are even found in elementary school, as demonstrated by Anyon's (1980) study, where working-class students and affluent students received remarkably different educational experiences. Even in kindergarten, informal streaming and tracking can begin. In Rist's (1977) ethnography on student labeling in an American kindergarten class, it took merely eight days for the teacher to develop permanent seating assignments based on presumed variations in academic ability. These seating arrangements reflected students' socioeconomic differences, with working-class students grouped together and middle-class students grouped together. Factoring into these distinctions were such things as the way a child was dressed, with poor dress associated with academic incapability and neatness in dress equated with an increased ability to learn. Rist (1977) followed these students from kindergarten to the second grade, and found that labels given in kindergarten had become self-fulfilling prophecies, eventually affecting students' placements into higher or lower tracks. Indeed, differential expectations on the part of teachers can significantly impact student learning.

When asked about their expectations for lower-track students, teachers emphasized conformity; for example, getting along with others, punctuality, working quietly, and following classroom rules (Oakes, 2005). From higher-track students, however, teachers expected independent work, creativity, critical thinking, self-direction, and active participation. In addition, teachers were found to be more enthusiastic and effective (clear and task-oriented) in higher-track classes (Oakes, 2005). Teachers also spent more class time giving instruction in higher-track classes and there was a greater average expected homework time than in lower-track classes. Not surprisingly, students in higher tracks reported more positive attitudes about themselves and higher aspirations than those in lower tracks (Oakes, 2005). 
Even if students in lower tracks have higher aspirations, they also have restricted mobility to higher tracks because of all the topics omitted from their curriculum (Oakes, 2005). This is a prime example of how selection processes in early education determine life outcomes. If a student is streamed into a low track and cannot switch into a higher track, their options for post-secondary attainment are quite limited. Processes of CAD are evident here, as the initial advantage of being in a higher track (or disadvantage of being in a lower track) creates a series of successive advantages or disadvantages. With social class being a particularly relevant variable in determining a student's placement into a given track, it appears that structural inequality is built into the school system. In addition, the argument can be made that this is an extension of the symbolic violence perpetuated against poor and working-class students. This, then, has implications for health throughout the life course, as individuals of low-income or working-class backgrounds are selected out of higher education by virtue of what happens in elementary and high school. This means that a much lower number of poor and working-class youth go on to post-secondary education than their middle- and upper-class counterparts.

If an individual's ability to pursue post-secondary education is restricted, he or she is not only prevented from acquiring additional cultural capital, but also, is prevented from turning such capital into monetary profit, amongst other things (Lamont \& Lareau 1998). Indeed, higher education is associated with greater income, another resource positively related to health (e.g. Mirowsky \& Ross, 2003). In addition, those with higher levels of education are less likely to be unemployed and more likely to work full-time (Wu \& Ross, 1995). Highly educated individuals also tend to acquire more fulfilling work in terms of autonomy and creativity, and have less exposure to physical, chemical or biological hazards in their work environment (Mirowsky \& Ross, 2003). Once again, these conditions are associated with better mental and physical health. Therefore, higher education provides numerous advantages in the labour market, which in turn affect health outcomes.

Higher education is also related to one's social-psychological resources (Wu \& Ross, 1995). While psychological resources in terms of learned effectiveness have already been discussed, what is important here is the fact that those with a higher education tend to have higher levels of social support. Indeed, the well-educated report more supportive relationships and are more likely to be married, both of which enhance health (Mirowsky \& Ross, 2003). Thus, the additional resources permitted by educational attainment in the forms of employment and income, as well as social support, can be viewed as complements to learned effectiveness. Together, all of these dimensions can shape health outcomes. Importantly, each is determined by an individual's level of educational success, which can be inhibited by the processes of streaming and tracking and symbolic violence. Consequently, educational institutions can serve as a system of class reproduction in which middle-class children are the most likely to succeed, and thus, to acquire the knowledge, skills, and additional resources that can be used to protect against physical and mental health decline throughout the course of their lives. Meanwhile, working-class children are more likely to experience cumulative disadvantage in that their initially worse-off social position is amplified by educational exclusion.

\section{Higher Education, Better Health}

Given the additional skills and resources that can be acquired through educational attainment, it is not surprising that education bears a strong relationship to health, nor that its absence can produce negative health consequences. In fact, of all socioeconomic indicators, education has consistently been demonstrated as "the most important predictor of health and mortality" (Ferraro, 2011: 469). In the United States, education has been found to be more important than both income/wealth and occupation in explaining the relationship between socioeconomic status and health (Mirowsky \& Ross, 2005). Even when income levels are controlled for, education retains its predictive power in that individuals with less education have poorer health outcomes than those with greater education at the same income level (Mirowsky \& Ross, 2003). Therefore, individuals with greater educational attainment generally have better health and live longer than those who have a high school education or less (Wu \& Ross, 1995; Deaton \& Paxton, 1999; Mirowsky \& Ross, 2003; Culter et al., 2008; Cutler \& Lieras-Muney, 2008; Elo 2009). For example, Meara et al. (2008) 
report that the life expectancy of those who have attended at least some college is approximately seven years higher than that of those who have completed high school or less. Thus, mortality rates tend to be lower for individuals who have completed more schooling.

Beyond its association with a lower mortality risk, education is also strongly correlated with higher levels of physical functioning and self-reported health, lower levels of morbidity and disability, lower rates of infectious and chronic diseases, and a later onset for chronic disease (Wu \& Ross, 1995; Crimmins, Hayward, \& Seeman, 2001; Lynch 2003; Smith 2007). Furthermore, figures reported by Rock et al. (2007) demonstrate that the incidence of smoking in the United States is much lower for those with an undergraduate degree at 9.6 percent in comparison to those with less education at 35.4 percent. In addition, individuals with higher educational attainment who do smoke are more likely to quit than their less educated counterparts (Wray et al. 1998). Those with higher education are also less likely to have experienced one or more psychiatric conditions in the past year (Mirowsky \& Ross, 2003; Thoits, 2005). Furthermore, when individuals of low and high social status experience the same mental health disorders, it is those who have greater educational attainment that are more likely to consult with a practitioner and seek some form of treatment (e.g. Thoits, 2005). Thus, even where class may not be enough to spare individuals from a particular condition, it can facilitate likelihood of treatment, and thus mediate severity. This can be viewed as an example of learned effectiveness in practice. Finally, higher educational attainment is positively associated with physical activity, which undoubtedly impacts many health outcomes, such as risk of cardiovascular disease, high blood pressure, and osteoporosis (Ford et al., 1991; Sandvik et al., 1993). It is therefore evident that the association between education and health is quite striking, and is largely attributable to the operation of capital acquired through its attainment.

It is clear that childhood circumstances have important implications for adult health outcomes, particularly through shaping one's educational experience. Specifically, childhood disadvantage decreases the likelihood of high educational attainment and therefore increases the likelihood of a negative health trajectory. On the other hand, childhood advantage facilitates educational attainment and the maintenance of positive health outcomes. This is not to say, however, that these processes are inevitable or incapable of alteration as cumulative disadvantage can be reversible under selected conditions. Specifically, the acquisition of particular resources can mediate the effects of early disadvantage on health. Education, for example, can operate as "a means for escaping previous disadvantage" (O'Rand 2009: 133). Indeed, Mirowsky and Ross (2003) report that educational attainment can largely improve the health outcomes of those disadvantaged individuals who are able to obtain it. Therefore, one's experience in the education system can be a significant turning point, changing the trajectory of one's life course (Laub \& Sampson, 1993; O'Rand, 2009). This, then, necessitates a strategy to increase access to and facilitate the completion of both high school and university or college by poor and working-class students.

\section{The DSBN Academy: A Turning Point?}

The DSBN Academy opened in September 2011 with 124 students. To attract students, 3000 application forms were distributed to elementary schools throughout the Niagara region and information sessions were conducted. All students whose parents did not have a post-secondary education could then apply. Importantly, the Academy can be viewed as an alternative to a mainstream school system in which students from poor and working-class backgrounds are largely disenfranchised. Indeed, the school's mandate centres on supporting and empowering students to attend and graduate not just from high school, but also from college or university (DSBN Academy, 2012). Accordingly, the Academy could be a key turning point for poor and working-class children as education, as reviewed above, has been proven to reduce the risk of unfavourable health outcomes (e.g. Howe \& Covell, 2011).

In order to provide its students with increased educational opportunities, the Academy is built upon several "strategies for success", including a single-track academic program. This means that students are not streamed into lower and higher tracks, but rather, are schooled in a singular track that would enable them to attend either university or college upon graduation. Consequently, many of the problems revealed previously with regard to streaming and tracking may be avoided, reducing the likelihood of a student being 
labeled based on their class situation instead of their abilities. Even though the Academy does not begin until grade six, informal streaming done by the child's former school prior to this could still be corrected by virtue of the fact that there is only one track for them to be placed in at the Academy. In this way, the labeling process that begins as early as kindergarten could be broken as it would not necessarily entail placement into a low track. Furthermore, the curriculum and quality of teaching would be consistent rather than as divergent as it is between higher and lower tracks in traditional schooling systems. Theoretically, students attending DSBN Academy would not be selected out of higher education, by virtue of placement in a lower track, in the manner they might be in a mainstream public school. The singe-track strategy, then, appears to be quite promising in its potential to alter the life course of disadvantaged students through facilitating their ability to enter post-secondary institutions and convert their education into other forms of capital.

In addition to a single-track curriculum, the DSBN Academy also features strategies of mandatory parental involvement, after school programs, transportation, a school-wide focus on post-secondary preparation, mentoring opportunities, and a breakfast and lunch program (DSBN Academy, 2012). Each of these components is associated with higher academic achievement, increased attendance, fewer disciplinary problems, and an increased likelihood of graduation (e.g. Desforges \& Abouchaar 2003; Jeynes, 2007; Grotz \& Grutzmacher, 2009; Grothaus \& Cole, 2010; Grant \& Ray, 2010; United States Government Accountability Office, 2010). Once again, the possibility of increasing educational attainment, and accordingly, improving health outcomes in later life for poor and working-class individuals is apparent. Furthermore, the Academy recognizes that students who face barriers to post-secondary education have a variety of needs, and thus takes a comprehensive approach that focuses on the whole student, rather than any singular aspect. As a result, the Academy may be able to legitimate the experiences of poor and working-class students in a way that the mainstream school system fails to do as a result of practices which institutionalize middle-class culture. Therefore, students who have grown up in an environment with limited social and cultural capital may not be as disadvantaged within the walls of the DSBN Academy. In other words, students' initial forms of capital may not impact their ability to proceed through the education system in the same way that it would in mainstream public schools, enabling them to acquire such skills as learned effectiveness, and in turn, improve their own health trajectories.

Essentially, the DSBN Academy advocates "achievement through opportunity," (DSBN Academy, 2012) and its design appears to offer students just that. That being said, the school is not without its weaknesses. The school has been criticized for increasing the segregation of students in the public school system and for possibly increasing the label and stigma associated with being a "disadvantaged" student (Beech, 2011; Bolichowski, 2011; Blizzard, 2011). Furthermore, critics have charged that such a school diverts resources from mainstream public schools, and also implies mainstream schools are performing inadequately. General concerns can also be raised regarding the challenges these students face when they come to university, including financial constraints (Berger, Motte, \& Parkin, 2007), feelings of not fitting in (Lehmann, 2008), and leaving university earlier than those students whose parents did go to university (Walpole, 2003; Lehmann, 2008).

Another issue of concern is that the Academy might encourage students to go to university who might be much happier in an apprenticeship and ultimately doing manual or blue-collar work (e.g. Lehmann, 2005). In this way, the school may be perpetuating a form of symbolic violence of its own in that it is adhering to a middle-class ideal of education, and ultimately, employment. Given the emphasis on postsecondary attainment, largely in the form of university (see DSBN Academy, 2012), it appears that the school could be encouraging working-class children to aspire to a middle-class standard of education. Its pedagogical strategies appear to be less about modifying the mainstream curriculum and more about changing the school climate. For example, one school board member states, "That's why DSBN Academy is here. We need to try something to make sure kids are going on to post-secondary education" (Bolichowski, 2011). In order to ensure this outcome, "[academy students] learn how to look for work, manage debt, find and apply for scholarships, and put cash away for the future" (Bolichowski, 2011). With an emphasis on post-secondary attainment, it appears that the school is focused on shaping its students in a particular manner. Indeed, "the curriculum is the same as at other schools in the DSBN, but [the principal] 
says the difference is in the extra efforts staff take to mold the students into young adults" (Gray, 2011). This is reminiscent of the concerted cultivation parenting approach revealed by Lareau (2003). Once more, middle-class ideals are perceptible. The school even goes so far as to alter students' appearances. As the principal notes, "We have high expectations in academics and attitudes, they come dressed for success" (Gray, 2011). Thus, students seem to be conditioned into a middle-class way of being.

Such a focus can overlook the significance of class differences through imposing middle-class standards of dress, working hard, accumulating wealth, and obtaining a university education. Essentially, the Academy aims to supplement the cultural capital (see Bourdieu, 2006) of its students through cultivating them into "responsible" young adults. Whether the students succeed or fail in this process is made their sole responsibility, as echoed by the school's creed which the students recite every day (see DSBN Academy, 2012). As a result, the Academy risks individualizing responsibility for success and failure while downplaying the role of social structure. This type of message may further exacerbate the situation of working-class students in the education system. The fact remains that while many people may view a limited education as a form of adversity, not every individual agrees, and many may not want this for themselves. The pedagogy of the DSBN Academy, then, must also be evaluated in terms of the agency it offers students, and whether or not teachers and administrators are aware of this middle-class bias. That said, increased educational attainment can certainly improve health outcomes and working-class individuals may wish for the opportunity to alter their own trajectories in this way.

In spite of its potential downfalls, then, the DSBN Academy could still be a turning point in the life paths of disadvantaged children until the mainstream system makes significant changes. If successful, the DSBN Academy model could also be adopted by mainstream schools in order to increase the life chances of all students. Research demonstrates that the life course trajectories for children from low socioeconomic backgrounds are generally unfavourable in terms of education and health. Thus, if the DSBN Academy can provide interested students with additional years of education, this could be quite beneficial. After all, Culter and Lleras-Muney (2006) report that even just an extra four years of schooling lowers mortality, reduces the risk of heart disease and diabetes, and lowers the probability of an individual reporting fair or poor health. Of course, the Academy must take caution to ensure that it offers students a chance to compete in the education system - and to acquire the resulting health benefits - without forcing them into the competition.

\section{Conclusion}

The association between education and health is quite clear. Indeed, higher education is positively related to better health, with individuals experiencing lower mortality and less chronic and infectious disease. The well-educated also engage in more health-enhancing behaviours, and are less likely to participate in healthaversive behaviours. Specifically, education can result in the development of learned effectiveness as well as the attainment of other resources such as income and social support. In both instances, education acts as a form of capital that ultimately enhances health. Indeed, those with a higher education are at a distinct advantage when it comes to health. Who becomes highly educated, however, is a very selective process that begins in early childhood. If one occupies an initially advantaged position in terms of class and capital, these advantages are likely to continue to accumulate over time, leading to favourable results in later life. Conversely, a child from a poor or working-class background is likely to encounter many barriers to higher education, and in turn, poorer health, as his or her relative disadvantage becomes exaggerated. Simply put, initial disadvantage at the outset determines the capital with which an individual begins school, and therefore, the capital he or she can gain through the education system in terms of learned effectiveness and additional resources. At the same time, an individual who is initially advantaged is more likely to have this position sustained as they successfully navigate the education system and obtain all that it has to offer.

This reality gives merit to the DSBN Academy, as it can offer a way to counter processes of cumulative disadvantage. Instead of limiting the potential to develop learned effectiveness and acquire other resources to those students in higher tracks (and of higher SES), the DSBN Academy can open the door for additional capital attainment through lessening the degree to which initial capital matters in educational 
success. That being said, the school is not without its limitations and may only be a short-term solution. More empirical and longitudinal research is certainly needed on the school itself, given that it is only in its first year of operation. Future research should concentrate on the Academy's success rate in terms of the post-secondary completion of its students. Students' perceptions surrounding the choices provided to them by the Academy and the impact of the Academy on their identities should also be evaluated. In addition, students' learned effectiveness could be measured at the time of entry to the Academy and again upon graduation from it, followed by measurement at the time of university or college completion. Finally, students' health trajectories could be modeled over time and compared to those of their parents. These are just a few suggestions, and there is certainly room for a great deal of future research surrounding the Academy and its implications for educational attainment and health.

As of right now, the DSBN Academy does bring attention to the fact that poor and working-class students face significant challenges in the education system. These challenges can have important implications for the life outcomes of these children, particularly in terms of health. Of course, it should be acknowledged that good health and higher education may not be desirable for everyone. The task for the Academy then lies in how the experiences of working-class students can be institutionally validated while at the same time not transformed into a middle-class habitus. This is not to say that all working-class students will feel this way or that some do not wish to further their education and align themselves with middle-class values. Rather, it is to point out that educational initiatives must be careful to avoid homogenizing working-class students as well as paternalistically prescribing which path they "should" follow. Indeed, any educational strategy geared toward these students must take this into consideration. The DSBN Academy certainly points toward the complexities of ameliorating inequality without perpetuating symbolic violence. The primary theoretical contribution of this paper, then, is that the education system can both reduce the effects of childhood disadvantage on health, but also, can simultaneously reproduce existing classed discourses surrounding what it means to be successful. The challenge, then, is how to effectively accomplish the former while reducing the effects of the latter.

It should also be noted here that education is only one piece of the puzzle. Clearly, changes must take places within all sectors of society if the life chances of disadvantaged individuals are to be improved. Nevertheless, the widening of social class inequalities in health in recent decades cannot be ignored. Education plays a key role in reducing such disparities, warranting further consideration of alternative strategies such as the DSBN Academy. The fact remains that any public health policy aimed at improving the health outcomes of disadvantaged groups must address the inequalities that emerge in early life, especially through the education system, if these trajectories are to be prevented from continuing into adulthood.

About the Author: Nicole Etherington is a Ph.D. student in the department of sociology at the University of Western Ontario. Her research interests include health inequality over the life course, education and health, cumulative (dis)advantage), and longitudinal research. She can be reached at: netherin@uwo.ca.

\section{References}

Anyon, J. (1980). Social class and the hidden curriculum of work. Journal of Education, 162, 6792.

Beech, M. (2011, February 1). Supporters stand with DSBN Academy, despite criticism of plan. The Standard. Retrieved from http://www.stcatharinesstandard.ca/ArticleDisplay.aspx?e $=2972951 \&$ archive $=$ true.

Berger, J., Motte, A, \& Parkin, A. (2007). The price of knowledge: Access and student finance in Canada. Montreal: The Canada Millenium Scholarship Foundation.

Blackwell, D.L., Hayward, M.D. \& Crimmins, E.M. (2001). Does childhood health affect chronic morbidity in later life? Social Science \& Medicine, 52(8), 1269-84. 
Blizzard, C. (2011, February 23). 'Poor school' a poor idea. Toronto Sun. Retrieved from http://www.torontosun.com/comment/columnists/christina_blizzard/ 2011/02/01/17117726.html.

Bolichowski, J. (2011, August 1). DSBN Academy: Building grades - and confidence. Niagara Falls Review. Retrieved from http://www.niagarafallsreview.ca/ ArticleDisplay.aspx?e=3207378).

Bourdieu, P., Passeron, J.C., \& Saint Martin, M. (1965). Academic discourse. Cambridge: Polity.

Bourdieu, P. (1974). The school as a conservative force: Scholastic and cultural inequalities. In J. Eggleston (Ed.), Contemporary Research in the Sociology of Education. London: Harper \& Row.

Bourdieu, P. (1979). Algeria 1960: The disenchantment of the world, the sense of honour, the Kabyle House, or the world reversed. Cambridge: University Press.

Bourdieu, P., Passeron, J.C., \& Nice, R. (1990). Reproduction in education, society, and culture. London: Sage Publications.

Bourdieu, P. (2006). The forms of capital. In A. R. Sadovnik (Ed.), Sociology of education: A Critical Reader (pp. 83-95). New York \& London: Routledge.

Crimmins, E. M., Hayward, M.D., \& Seeman, T.E. (2001). Race/ethnicity, socioeconomic status and health. In N.B. Anderson, R.A. Bulato, \& B. Cohen (Eds.), Critical perspectives on racial and ethnic differences in health in late life (310-352). Washington, DC: National Academic Press

Cutler, D. M. \& Lleras-Muney, A. (2006). Education and health: Evaluating theories and evidence. Cambridge, MA: National Bureau of Economic Research.

Cutler D.M., Lleras-Muney, A., \& Vogl, T. (2008). Socioeconomic status and health: Dimensions and mechanisms. Cambridge, MA: National Bureau of Economic Research.

Deaton, A. \& Paxton, C. (1999). Mortality, education, income, and inequality among American cohorts. Cambridge, MA: National Bureau of Economic Research.

Desforges, C. \& Abouchaar, A. (2003). The impact of parental involvement, parental support and family education on pupil achievement and adjustment: A literature review. London: Department for Education and Skills.

DSBN Academy. (2012). Achievement through Opportunity. Retrieved from http://academy.dsbn.org/.

Elman, C. \& O'Rand, A.M. (2004). The race is to the swift: Socioeconomic origins, adult education, and wage attainment. American Journal of Sociology, 110, 123-160.

Elo, I. T. (2009). Social class differentials in health and mortality: Patterns and explanations in comparative perspective. Annual Review of Sociology, 35, 553-572.

Ferraro, K. F. (2011). Health and aging: Early origins, persistent inequalities? In R.A. Settersten \& J.L. Angel (Eds.), Handbook of Sociology of Aging, Ch. 29. New York: Springer.

Ford, E. S., Merritt, R.K., Heath, G.W., Powell, K.E., Washburn, R.A., Kriska, A., \& Haile, G. (1991). Physical activity behaviors in lower and higher socioeconomic status populations. American Journal of Epidemiology, 133, 1246-1255.

Galobardes, B., Lynch, J.W. \&. Smith, J.D. (2004). Childhood socioeconomic circumstances and cause-specific mortality in adulthood: Systematic review and Interpretation. Epidemiological Reviews, 26,7-21.

Goldman, D. \& Smith, J.P. (2002). Can patient self-management help explain the SES health gradient? Proceedings of the National Academy of Sciences of the United States of America, 99, 10929-10934

Graham, H. \& Power, C. (2004). Childhood disadvantage and health Inequalities: A framework for policy based on lifecourse research. Childcare, Health and Development, 30(6),671-8.

Grant, K.B. \& Ray, J.A. (2010). Home, school and community collaboration: Culturally responsive family involvement. Los Angeles: Sage.

Gray, V. (2011, December 31). DSBN Academy - a mid-term report card. Niagara Falls Review. Ret. from: http://www.niagarafallsreview.ca/ArticleDisplay.aspx?e=3421246

Grenfell, M. (2009). Bourdieu, language, and literacy. Reading Research Quarterly, 44, 438-448. 
Grothaus, T. \& Cole, R. (2010). Meeting the challenges together: School counselors collaborating with students and families with low income. Journal of School Counseling, 8, 1-23.

Gross, S.M., \& Grutzmacher, S. (2009). Household food security and fruit and vegetable intake among low-income $4^{\text {th }}$ graders. Journal of Nutrition Education and Behaviour, 41.

Haas, S. A. (2006). Health selection and the process of social stratification: The effect of childhood health on socioeconomic attainment. Journal of Health and Social Behavior, 47, 339354.

Halasz, J. R. \& Kaufman, P. (2008). Sociology as pedagogy: How ideas from the discipline can inform teaching and learning. Teaching Sociology, 36, 301-317.

Hammer, K. (2011, February 26). A ticket to university or segregation of the poor? Globe and Mail, p. A16.

Hatch, S. L. (2005). Conceptualizing and identifying cumulative adversity and protective resources: Implications for understanding health inequalities. Journals of Gerontology, 60, 130134.

Hayward, M.D. \& Gorman, B.K. (2004). The long arm of childhood: The influence of early-life social conditions on men's mortality. Demography, 41, 87-107

Hillmert, S. \& Jacob, M. (2010). Selections and social selectivity on the academic track: A lifecourse analysis of educational attainment in Germany. Research in Social Stratification and Mobility, 28, 59-76.

House, J. S. (2001). Understanding social factors and inequalities in health: 20th century progress and 21 st century prospects. Journal of Health and Social Behavior, 43, 125-142.

Howe, B.R. \& Covell, K. (2011). Countering disadvantage, promoting health: The value of children's human rights education. The Journal of Educational Thought, 45, 59-85.

Jeynes, W. (2007). The relationship between parental involvement and urban secondary school student academic achievement: A meta-analysis. Urban Education, 42, 82-110.

Kalache, A. \& Kickbusch, I. (1997). A global strategy for healthy aging. World Health, 50, 4-5.

Kaufman, P. (2003). Learning to not labor: How working-class individuals construct middleclass identities. The Sociological Quarterly, 44, 481-504.

Knighten, T. \& Mirza, S. (2002). Post-secondary participation: The effects of parents' education and household income. Education Quarterly Review, 8, 25-32.

Knobel, M. \& Lankshear, C. (2003). Researching young children's out-of-school literacy practices. In N. Hall, J. Larson, \& J. Marsh (Eds.), Handbook of Early Childhood Literacy, (5165). Thousand Oaks, CA: Sage.

Lambert, M., Zeman, K., Allen, M., \& Bussiere, P. (2004). Who pursues post-secondary education, who leaves, and why: Results from the youth in transition survey. Ottawa: Statistics

Canada \& Human Resources and Skills Development Canada.

Lamont, M. \& Lareau, A. (1988). Cultural capital: Allusions, gaps and glissandos in recent theoretical developments. Sociological Theory, 6, 153-168.

Lareau, A. (2003). Unequal childhoods: class, race, and family life. Berkeley: University of California Press.

Lareau, A. \& Weininger, E.B. (2003). Cultural capital in educational research: A critical assessment. Theory and Society, 32, 567-606.

Laub, J.H. \& Sampson, R.L. (1993). Turning points in the life course: Why change matters to the study of crime. Criminology, 31, 301-325.

Lehmann, W. (2008). University as vocational education: Working-class students' expectations for university. British Journal of Sociology of Education, 30, 137-149.

Lieberson, S. (1985). Making it count. Berkeley: University of California Press.

Link, B.G. \& Phelan, J.C. (1995). Social conditions as fundamental causes of disease. Journal of Health and Social Behavior, 35, 80-94.

Lynch, S.M. (2003). Cohort and life-course patterns in the relationship between education and health: A hierarchical approach. Demography, 40, 309-31. 
Lleras-Muney, A. \& Lichtenberg, F. (2002). The effect of education on medical technology adoption: Are the more educated more likely to use drugs? Cambridge, MA: National Bureau of Economic Research.

Luke, A. \& Luke, C. (2001). Adolescence lost/childhood regained: On early intervention and the emergence of the techno-subject. Journal of Early Childhood Literacy, 1, 91-120.

Marsh, J. (2006). Popular culture in the literacy curriculum: A Bourdieuan analysis." Reading Research Quarterly, 41, 150-174.

McLeod, J.D. \& Pavalko, E.K. (2008). From selection effects to reciprocal processes: What does attention to the life course offer? Stress Processes Across the Life Course, 13, 75-104.

Meara, E. R., Richards, S., \& Cutler, D.M. (2008). The gap gets bigger: Changes in mortality and life expectancy, by education 1981-2000. Health Affairs, 27, 350-360

Mirowsky, J. \& Ross, C.E. (2003). Education, social status and health. New York: Walter de Gruyter, Inc.

Mirowsky, J. \& Ross, C.E. (2005). Education, learned Effectiveness, and health. London Review of Education, 3, 205-220.

Mirowsky, J., Ross, C.E., \& Reynolds, J. (2000). Links between social status and health status. In C. Bird, P. Conrad, \& A. Fremont, Handbook of Medical Sociology, (47-67). New Jersey: Prentice-Hall, Inc.

Mishra, G., Ball, K., Dobson, A., \& Byles, J. (2004). Do socioeconomic gradients in women's health Widen over time and with age? Social Science and Medicine, 58, 1585-1595.

Oakes, J. (2005). Keeping track: How schools structure inequality. New Haven: Yale University Press.

O'Rand, A. (1996). The precious and the precocious: Understanding cumulative disadvantage and cumulative advantage over the life course. The Gerontologist, 36, 230-238.

O'Rand, A. (2009). Cumulative processes in the life course. In J.Z. Giele \& G.H. Elder (Eds.), The craft of life course research, pp. 121-140

O'Rand, A. \& Hamil-Luker, J. (2005). Processes of cumulative adversity: Childhood disadvantage and increased risk of heart attack across the life course." Journals of Gerontology, 60, 117-124.

Packard, C.J. et al. (2011). Early life socioeconomic adversity is associated in adult life with chronic inflammation, carotid atherosclerosis, poorer lung function and decreased cognitive performance: A cross-sectional, population-based study. BMC Public Health, 11, 42-58.

Pampel, F. C. (2009). The persistence of educational disparities in smoking. Social Problems, 56, 526-542.

Pampel, F. C., Krueger, P.M., \& Denney, J.T. (2010). Socioeconomic disparities in health behaviours. Annual Review of Sociology, 36, 349-370.

Paeratakul, S., White, M., Williamson, D., Ryan, D. \& Bray, George. (2002). Sex, race/ethnicity, socioeconomic status, and BMI in relation to self-Perception of overweight. Obesity Research, $10,345-350$

Phelan, J.C., Link, B.G. \& Tehranifar, P. (2010). Social conditions as fundamental causes of health inequalities: Theory, evidence, and policy implications. Journal of Health and Social Behaviour, 51, 528-540.

Poulton, R. et al. (2002). Association between children's experience of socioeconomic disadvantage and adult health: A life-course study. Lancet, 360, 1640-1645.

Prus, S.G. (2007). Age, SES, and health: A populaton level analysis of health inequalities over the life course. Sociology of Health and Illness, 29, 275-296.

Rist, R.C. (1977). On understanding to processes of schooling: The contributions of labeling theory. In J. Jarabel \& A.H. Halsey (Eds.), Power and ideology in education, Ch. 15. New York: Oxford University Press.

Rock, V. J., Malarcher, A., Kahende, J.W., Asman, K., Husten, C. \& Caraballo, R. (2007). Cigarette smoking among adults: United States, 2006.” MMWR, 56, 1157-1161. 
Roscigo, V. J. \& Ainsworth-Darnell, J.W. (1999). Race, cultural capital, and educational resources: Persistent inequalities and achievement returns. Sociology of Education, 72, 158-178.

Ross, C. E. \& Van Willigen, M. (1997). Education and the subjective quality of life. Journal of Health and Social Behavior, 38, 275-297.

Sandvik, L., Erikssen, J., Thaulow, E., Erikssen, G., Mundal, R., \& Rodahl, K. (1993). Physical fitness as a predictor of mortality among healthy, middle-aged Norwegian men. New England Journal of Medicine, 328, 533-537.

Schieman, S. (2001). Age, education, and the sense of control: A test of the cumulative advantage hypothesis. Research on Aging, 23, 153-178.

Seabrook, J.A. \& Avison, W.R. (2012). Socioeconomic status and cumulative disadvantage processes across the life course: Implications for health outcomes. Canadian Review of Sociology, $49,50-68$.

Smith, J.P. (2005). Unraveling the SES-health connection. Population Development Review, 30, $108-132$

Smith, J.P. (2007). The impact of socioeconomic status on health over the life-course. Journal of Human Resources, 42, 739-764.

Svanes, C. et al. (2010). Early life origins of chronic obstructive pulmonary disease. Thorax, 65, $14-20$.

Thoits, P.A. (2005). Differential labeling of mental illness by social status: A new look at an old problem. Journal of Health and Social Behavior, 46, 102-119.

Thoits, P.A. (2006). Personal agency in the stress process. Journal of Health and Social Behavior, 47, 309-324

Toshalis, E. (2010). From disciplined to disciplinarian: The reproduction of symbolic violence in pre-service teacher education. Journal of Curriculum Studies, 42, 183-213.

United States Government Accountability Office. (2010). Many challenges arise in educating students who change schools frequently. Washington: Government Accountability Office.

Walpole, M. (2003). Socioeconomic status and college: How SES affects college experiences and outcomes. Review of Higher Education, 27, 45-73.

Willson, A.E., Shuey, K.M. \& Elder, G.H. (2007). Cumulative advantage processes as mechanisms of inequality in life course health. American Journal of Sociology, 112, 1886-1924.

Wray, L. A., Herzog, A.R., Willis, R.J., \& Wallace, R.B. (1998). The impact of education and heart attack on smoking cessation in middle-aged adults. Journal of Health and Social Behavior, 39, 271-294

Wu, C. \& Ross, C.E. (1995). The links between education and health. American Sociological Review, 60, 719-745. 